\title{
Evaluating the effectiveness of school garden-based programme in addressing knowledge, attitudes and practices on nutrition and diet of school children aged 3-18: a systematic review
}

School garden-based programmes have shown positive impacts on children's knowledge, attitudes and practices towards healthy eating and lifestyle which are the key component for children's physical wellbeing and cognitive development ${ }^{(1)}$. Using a hands-on experimental approach, it provides opportunities for the children to access and grow their own fruit and vegetable (F\&V) and increase their awareness on healthy diet. These activities may increase children's preferential selection, willingness to taste, and potentially the intake of $\mathrm{F} \& \mathrm{~V}^{(2)}$. Despite a great promise shown, evidence on the literature towards its effectiveness remains inconsistent ${ }^{(1,3)}$. Therefore, this review aimed to summarise and evaluate the current evidence on the impacts of school garden-based programme on knowledge, attitudes and practises on nutrition and diet of school children, and to explore the key features of effectiveness.

5 databases including PubMed, Scopus, Embase (Ovid), Cochrane Library, Web of Science and Scopus were searched since 11th November 2020 until 6th February 2021. Randomised, non-randomised controlled and pre-post intervention studies focusing on school garden-based programmes (indoor or outdoor) among school children aged 3-18 years old ( $\pm 1 \mathrm{y}$ ) were included. Studies that reported at least one outcome of interest such as diet and nutrition-related knowledge, attitudes, skills, preferences towards $\mathrm{F} \& \mathrm{~V}$ as well as food diversity, dietary practices and intake especially F\&V were included. Selection of studies and data extraction were performed by one reviewer and checked for accuracy by two other reviewers in accordance with PRISMA guideline.

A total of 10,836 records were identified and 5,922 records were excluded due to duplication. Of those remaining 4,914 articles, 35 studies met the inclusion and exclusion criteria. Overall, 25,726 students from 341 schools and 8 nursery centres from 12 different countries were included in this review. The intervention duration ranged from 8 weeks to 4 years. Most of the school garden-based programmes include other activities such as cooking session, nutritional education, and parental involvement. 17 studies reported positive impacts of school garden-based programmes on nutrition and garden-related knowledge, while 3 studies reported no significant effect. 16 studies demonstrated improvement in attitudes, preferences and taste rating towards F\&V, whereas no significant effect was found in 5 studies. 6 and 13 studies reported a significant increase in the intakes of fruit and vegetable, respectively. However, such effects were not found in other 10 and 12 studies, respectively. Risk of publication bias will be assessed using the American Dietetic Association Quality Criteria Checklist and will be discussed.

School-garden based interventions have shown beneficial effects on children's knowledge, attitudes and preference towards F\&V. However, there is no strong evidence supporting its beneficial effect on actual F\&V consumption. Effects of school garden-based programme on increasing children's F\&V intake remain debatable.

\section{References}

1. Ratcliffe MM, Merrigan KA, Rogers BL, et al. (2011) Health Promot Pract 12, 36-43.

2. Bontrager Yoder AB, Liebhart JL, McCarty DJ, et al. (2014) J Nutr Educ Behav 46, 341-349.

3. Gatto NM, Martinez LC, et al. (2017) Pediatr Obes 12, 28-37. 